\title{
A compact city for the wealthy? Employment accessibility inequalities between occupational classes in the London metropolitan region 2011
}

\author{
Duncan A. Smith ${ }^{\mathrm{a}, *}$, Yao Shen ${ }^{\mathrm{b}}$, Joana Barros ${ }^{\mathrm{c}}$, Chen Zhong ${ }^{\mathrm{d}}$, Mike Batty ${ }^{\mathrm{a}}$, Mariana Giannotti ${ }^{\mathrm{e}}$ \\ ${ }^{a}$ Centre for Advanced Spatial Analysis (CASA), University College London, W1T 4TJ, London, UK \\ ${ }^{\mathrm{b}}$ Department of Urban Planning, Tongji University, 1239 Siping Road, Shanghai 200092, China \\ ${ }^{\mathrm{c}}$ Department of Geography, Birkbeck, University of London, WC1E 7HX, London, UK \\ ${ }^{\mathrm{d}}$ Department of Geography, Kings College London, Strand, WC2R 2LS, London, UK \\ ${ }^{\mathrm{e}}$ Geoprocessing Laboratory, University of São Paulo (USP), Av. Prof. Luciano Gualberto, São Paulo, Brazil
}

\section{A B S T R A C T}

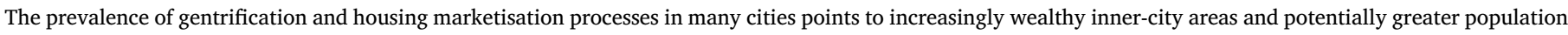

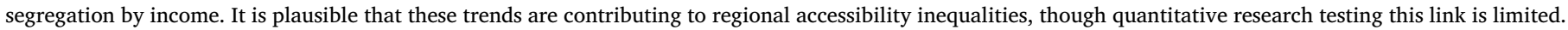

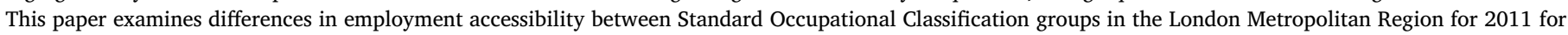

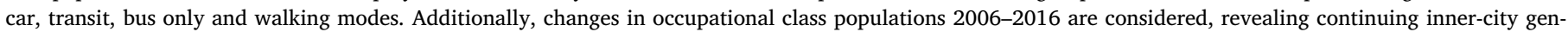

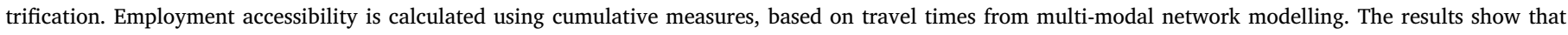

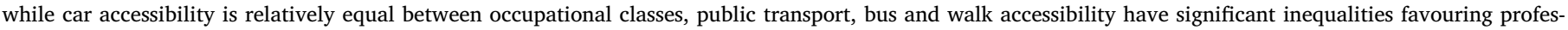

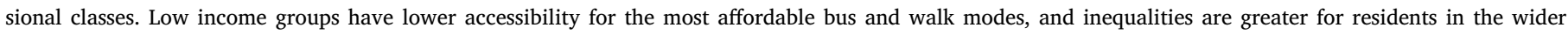

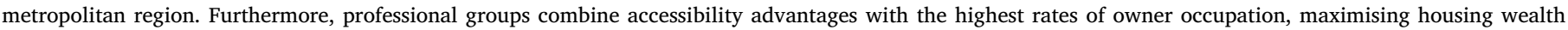

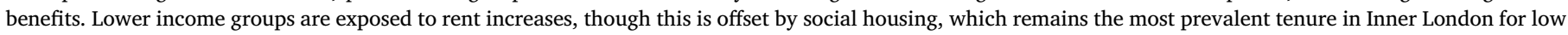
income classes.

\section{Overview}

The aim of this paper is to analyse employment accessibility inequalities between occupational classes in the London Metropolitan Region for the last census year 2011, and to quantify the extent of journey-to-work accessibility differences by the main transport modes in the study area. London has been transformed in recent decades through gentrification (Davidson and Lees, 2005; Hamnett, 2003). High accessibility inner-city areas have become increasingly dominated by professional classes, potentially resulting in accessibility advantages for more affluent groups. The increasingly elite nature of many inner-cities has been widely discussed (Ehrenhalt, 2012; Florida, 2017), yet research quantifying related accessibility impacts is limited. Relevant literature is reviewed in Section 2, discussing disaggregate accessibility studies, methods for calculating accessibility measures, and gentrification research.

This paper focusses on cumulative residential accessibility to employment through morning peak journey-to-work, with the methodology set out in Section 3. The research results are split into two sections, with Section 4 analysing residential location by occupational class, and Section 5 presenting the accessibility results. Finally, conclusions are provided in Section 6.

\section{Literature review}

\subsection{Disaggregate accessibility analysis methods}

Accessibility describes the extent to which land uses and transport systems enable individuals or groups to reach activities by transport modes (Geurs and van Wee, 2004). Differences in accessibility can be considered at the individual level following space-time geography approaches (Kwan, 1998), or for socio-economic groups following location-based approaches (Grengs, 2012; Shen, 1998; Wachs and Kumagai, 1973). The main focus of accessibility studies by socio-economic groups is equity: evaluating opportunities between or within groups, and whether particular groups have higher costs to reach services. Geographical accessibility barriers can be significant in many cities, and are interrelated with various social and political factors influencing inequality (Church et al., 2000). It is also important to recognise the economic and sustainability dimensions of accessibility, in relation to

\footnotetext{
* Corresponding author.

E-mail addresses: duncan.a.smith@ucl.ac.uk (D.A. Smith), y.shen.12@ucl.ac.uk (Y. Shen), j.barros@bbk.ac.uk (J. Barros), chen.zhong@kcl.ac.uk (C. Zhong), m.batty@ucl.ac.uk (M. Batty), mariana.giannotti@usp.br (M. Giannotti).
} 
productivity and labour market access (Cervero, 2001), and transit and active travel mode competitiveness (Benenson et al., 2011; Ford et al., 2015). Planning policy aims to find synergies in equity, efficiency and sustainability, though there are often complicated trade-offs to consider (Geurs et al., 2016).

There are a range of methods for measuring accessibility (Geurs and van Wee, 2004; Handy and Niemeier, 1997). Fundamental considerations include how travel costs are modelled (e.g. time or generalised cost) and which transport modes and trip purposes are considered. This paper uses location-based measures, that is accessibility for defined locations to spatially distributed activities (Geurs and van Wee, 2004). The impedance function that weights opportunities by travel costs is an important choice for location measures. Cumulative functions sum the opportunities within fixed cost thresholds (Boisjoly and El-Geneidy, 2017; Pereira et al., 2018), while gravitational functions apply distance decay parameters in the tradition of Hansen (1959). Cumulative measures have advantages for comparative analysis, as they are expressed in easily understood units, and minimise a-priori behavioural assumptions (Neutens et al., 2010). They are however very sensitive to threshold selection and lack competition effects (Geurs and van Wee, 2004). Gravitational functions are more sophisticated and require the calibration of distance-decay parameters. This adds to the complexity of comparative analysis where multiple modes and socio-economic groups are considered.

Competition effects weight the attractiveness of opportunities by estimating demand (Shen, 1998). Where opportunities are demand sensitive with local catchments, such as primary healthcare (Luo and Qi, 2009), the rationale for considering local competition is strong. For studies of employment accessibility, the more regional nature of labour market competition makes the argument for weighting opportunities by local catchments less clear. A related issue is whether employment accessibility measures should be disaggregated by different types of jobs, which can be used to identify spatial mismatches in employment opportunities (Cervero et al., 1999). Disaggregate measures provide a more accurate picture for workers in particular sectors, while accessibility to all jobs relates to more general measures of location potential.

\subsection{Accessibility, urban spatial structure and gentrification}

The results of location-based accessibility equity studies are generally closely related to urban spatial structure. In traditional monocentric urban models, lower income groups are concentrated in smaller inner-city housing closer to CBDs, while more affluent groups favour larger suburban housing (Alonso, 1964; Anas et al., 1998). Studies of US industrial cities that largely correspond to this model, including Detroit (Grengs, 2012) and Boston (Shen, 1998), identify accessibility advantages for low income groups concentrated in the inner-city, although these are offset by limited transit services and restricted car ownership (Grengs, 2012; Shen, 1998). Many cities diverge considerably from the monocentric model, and therefore accessibility results are also likely to diverge. Affluent historic cores characterise European cities such as Madrid (Bueno Cadena et al., 2016) and Paris, and weaker jobs accessibility for low income groups has been identified in Paris (Korsu and Wenglenski, 2010). US cities with more polycentric urban structures also diverge from the monocentric model. Cervero et al. (1999) found accessibility advantages for higher income occupational classes in the San Francisco Bay Area, and that these advantages were increasing over time, while jobs accessibility advantages for more affluent groups have also been found in Los Angeles ( $\mathrm{Hu}$, 2017). In the London context, accessibility studies have considered transport sustainability (Ford et al., 2015), accessibility of new infrastructure (Sánchez-Mateos and Givoni, 2012), and general relationships between transport and social exclusion (Church et al., 2000), but studies of comparative accessibility measures for different income or occupational classes have to the best of our knowledge not been published.
Inner-cities typically play a key role in accessibility outcomes for lower income groups as this is traditionally the area where accessibility is highest. As the problems of pollution and crime have lessened in many post-industrial contexts, inner-cities have in many cases been transformed through gentrification. Gentrification is defined by Hamnett (2003) as "the social and spatial manifestation of the transition from an industrial to a post-industrial urban economy" (Hamnett, 2003, p.2402), whereby an expanded middle class begins to locate in areas of well-built, low-priced, inner-city districts occupied by working classes. Neo-Marxist interpretations of gentrification emphasise capital accumulation, where gentrifiers exploit the difference between initial house prices in run-down neighbourhoods and the longer term location potential (Smith, 1979). This value-uplift depends on gentrification being spatially clustered, such as in London, where gentrification was first observed in Inner-West London in the 1960s (Glass, 1964), and then spread eastwards (Hamnett, 2003). The value-uplift perspective also aligns with the aims of real-estate developers, and researchers have observed the increasing importance of new-build gentrification processes (Davidson and Lees, 2010), with areas of major housing development targeting affluent buyers.

The quantitative measurement of gentrification is often based on a definition of socio-economic class, using classification schemes such as the UK NS-SEC (Rose and Pevalin, 2010). Housing tenure is another relevant variable, as gentrifiers typically purchase houses in areas where renting is prevalent. In the UK, renting declined significantly from the 1960s onwards (Hamnett, 2003), though has increased again in the early 21 st century, potentially indicating that gentrification processes have stabilised (Manley and Johnston, 2014) or evolved into a new phase (Davidson and Lees, 2010). Social rented housing provides discounted rents that minimise displacement pressures, but this sector has been in decline for decades in London in the face of privatisation policies from national and local government (Watt, 2009).

\section{Methodology}

\subsection{Study region and sub-region definitions}

A regional study area is investigated in this paper, extending beyond the municipal boundary of the Greater London Authority (GLA) as shown in Fig. 1. The rationale for this larger study area is that journeyto-work trips extend beyond the GLA (Hall and Pain, 2006; Reades and Smith, 2014), with over 1 million trips crossing the GLA boundary every working day (Smith, 2018). This degree of interaction is evidence of regional integration in terms of labour and housing markets. The London Metropolitan Region has been defined using a 10\% commuting threshold to the GLA at the Middle Super Output Area (MSOA) scale (Smith, 2018), incorporating several towns which are an hour's rail travel from London. The Metropolitan Region is divided into the following sub-regions: the Outer Metropolitan Area (OMA), and the Inner GLA and Outer GLA, based on the London Plan (Mayor of London, 2016).

The London Metropolitan Region total population was 16.9 million in 2016 as shown in Table 1, with $8.8 \mathrm{~m}$ or $52 \%$ of the total within the GLA. The GLA has a larger residential population in the Outer GLA, while the Inner GLA is the major employment centre, with a total of 2.7 million jobs in 2011. This largely monocentric geography produces a strong radial commuting pattern, enabled by the radial transport networks shown in Fig. 1. The population of the entire London Metropolitan Region grew by 1 million people between 2011 and 2016, with the highest percentage growth in the Inner GLA. The working population 2011 shown in Table 1 is the base population used for all the 2011 occupational class and accessibility analysis in this paper.

\subsection{Standard occupational classification 2010 overview}

The demographic disaggregation in this paper is based on 


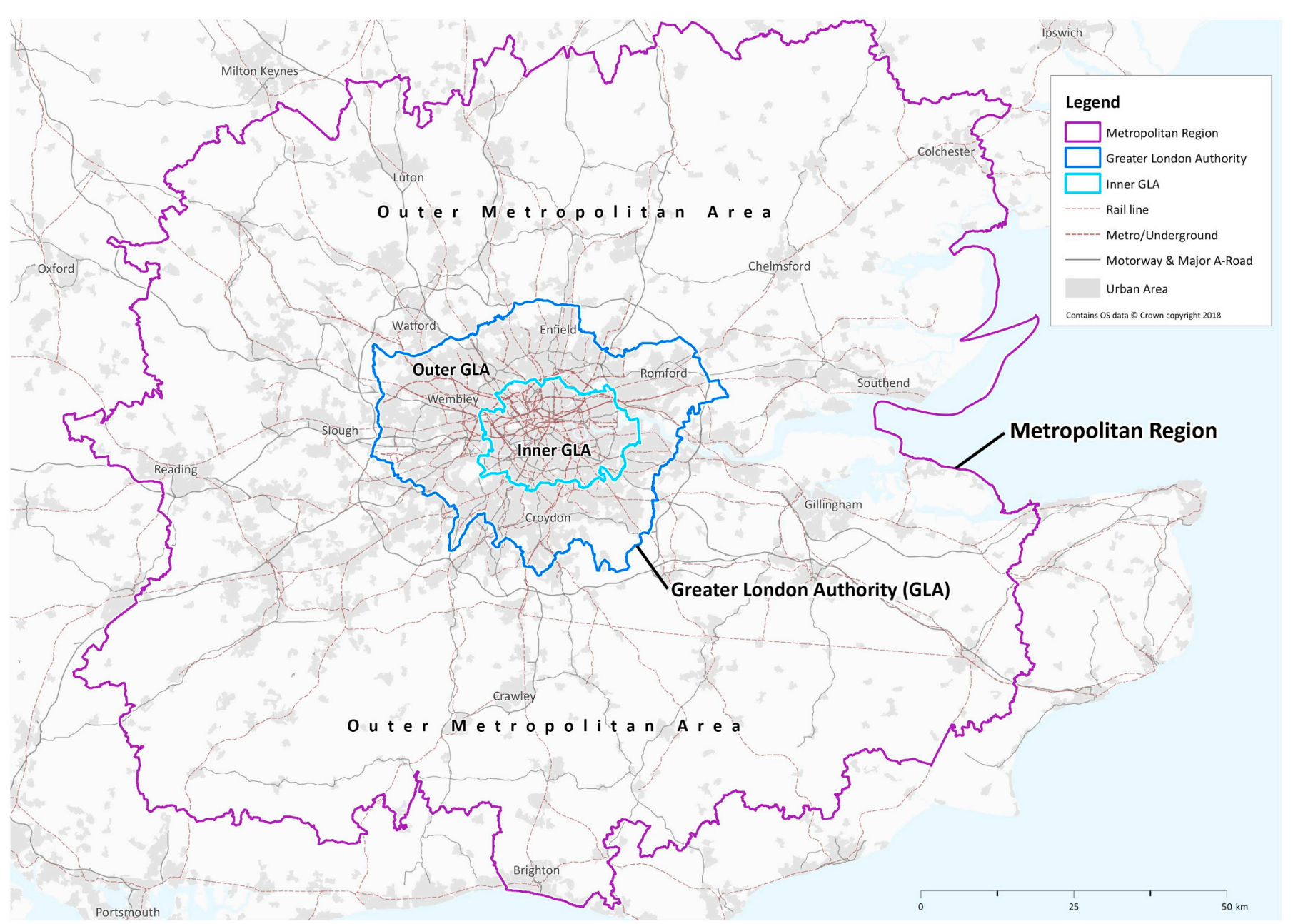

Fig. 1. London Metropolitan Region Geography and Sub-Regions.

Table 1

Population of study area region and sub-regions.

\begin{tabular}{lllllll}
\hline & $\begin{array}{l}\text { Total Area } \\
\left(\mathrm{km}^{2}\right)\end{array}$ & $\begin{array}{l}\text { Population 2011 } \\
(000 \text { 's }\end{array}$ & $\begin{array}{l}\text { Population 2016 } \\
(000 \text { 's })\end{array}$ & $\begin{array}{l}\text { Pop. Change 2011-2016 } \\
(000 \text { 's })\end{array}$ & $\begin{array}{l}\text { Working Pop. 2011 } \\
(000 \text { 's })\end{array}$ & $\begin{array}{l}\text { Jobs by Workplace 2011 } \\
(000 ' s)\end{array}$ \\
\hline Metropolitan Region & 16,782 & 15,946 & 16,941 & $995(6.2 \%)$ & 7886 & 8069 \\
Greater London Authority & 1569 & 8159 & 8773 & $614(7.5 \%)$ & 3992 & 4496 \\
Inner GLA & 348 & 3224 & 3523 & $299(9.3 \%)$ & 1627 & 2662 \\
Outer GLA & 1221 & 4935 & 5250 & $315(6.4 \%)$ & 2365 & 1834 \\
Outer Metro. Area & 15,213 & 7787 & 8168 & $382(4.9 \%)$ & 3895 & 3573 \\
\hline
\end{tabular}

Data sources: Census 2011 (Office for National Statistics, 2016); Small area population estimates 2016 (Office for National Statistics, 2017a).

occupational class, specifically the Standard Occupational Classification (SOC) 2010 (Elias and Birch, 2010). SOC is preferred to the National Statistics Socio-Economic Classification (NS-SEC) for two main reasons. Firstly, SOC major groups were found to perform better at discriminating professional classes in the study area. SOC has three professional major groups as shown in Table 2, while the NS-SEC group 1.2 (lower professional) comprises a huge $33 \%$ of the study area working population. The second reason is that SOC data is available through the Annual Population Survey, which allows analysis of recent changes after the 2011 census year. Table 2 shows median incomes for the SOC groups, showing a good correspondence with the SOC hierarchy, although note that SOC Group 8 is an outlier. The SOC classification does not identify unemployed populations, or specifically identify groups in poverty. The intention in this paper is to analyse general relationships between accessibility and income classes based on occupational class. There are shortcomings with the SOC data, with considerable income variation within classes, but given the lack of income data in the UK census it is a suitable starting point for disaggregate analysis.

\subsection{Travel costs modelling overview}

Travel costs are based on modelling travel times by different modes during the morning peak, $7 \mathrm{am}-10 \mathrm{am}$. A public transport model has been developed using the OpenTripPlanner ${ }^{1}$ software. The full rail, underground and bus timetable is included, with comprehensive multimodal transit interchanges allowed, and the street network used for walk stages. OpenTripPlanner uses a generalised cost approach for transit routing that captures important behaviours such as avoiding

\footnotetext{
${ }^{1}$ OpenTripPlanner is an open source multi-modal journey planner, seehttps://github.com/opentripplanner/OpenTripPlanner
} 
Table 2

SOC 2010 major groups residential percentages 2011 and median Income 2016.

\begin{tabular}{|c|c|c|c|c|c|}
\hline Major group name & Group description & London metro region $\% 2011$ & GLA \% 2011 & GLA weekly median income $2016(£)^{\mathrm{a}}$ & Mean age \\
\hline 1. Manag. & Managers, directors and senior officials & 12.3 & 12.7 & 1125 & 44 \\
\hline 2. Profes. & Professional occupations & 20.6 & 22.8 & 824 & 43 \\
\hline 3. AssoProf. & Associate professional and technical occ. & 15.5 & 17.3 & 674 & 41 \\
\hline 4. Admin. & Administrative and secretarial occupations & 11.9 & 12.1 & 517 & 43 \\
\hline 5. SkillTrd. & Skilled trades occupations & 9.5 & 7.8 & 522 & 42 \\
\hline 6. OtherServ. & Caring, leisure and other service occ. & 8.3 & 7.3 & 403 & 40 \\
\hline 7. Sales. & Sales and customer service occupations & 7.5 & 6.8 & 401 & 34 \\
\hline 8. Process. & Process, plant and machine operatives & 5.3 & 4.6 & 560 & 45 \\
\hline 9. Element. & Elementary occupations & 9.3 & 8.7 & 371 & 38 \\
\hline
\end{tabular}

Data sources: Census 2011 (Office for National Statistics, 2016); Annual Survey of Hours and Earnings 2016 (Office for National Statistics, 2017b).

a GLA Gross Weekly Median Income, Full-Time employees only 2016.

Table 3

London metro region journey-to-work main mode ${ }^{1}$ by occupational class 2011.

\begin{tabular}{|c|c|c|c|c|c|c|c|c|}
\hline & Car & $\begin{array}{l}\text { Rail \& } \\
\text { Metro }\end{array}$ & Bus & Walking & Cycling & Other & $\begin{array}{c}\text { Average } \\
\text { Distance } \\
(\mathbf{k m})^{2}\end{array}$ & $\begin{array}{l}\text { Jobs \% in } \\
\text { Inner GLA }\end{array}$ \\
\hline 1.Manag & 53.7 & 29.1 & 5.1 & 6.8 & 2.9 & 2.3 & 15.0 & 37.9 \\
\hline 2.Prof & 46.7 & 33.7 & 6.2 & 7.5 & 4.4 & 1.6 & 13.7 & 41.6 \\
\hline 3.AssocP & 43.2 & 37.0 & 6.2 & 6.9 & 4.2 & 2.4 & 14.7 & 43.5 \\
\hline 4.Admin & 48.2 & 29.2 & 10.3 & 9.4 & 1.8 & 0.9 & 11.6 & 35.3 \\
\hline 5.SkilledT & 68.0 & 15.5 & 6.2 & 5.2 & 2.8 & 2.2 & 12.6 & 18.7 \\
\hline 6.0therS & 52.4 & 12.7 & 15.1 & 16.3 & 2.2 & 1.3 & 8.5 & 22.4 \\
\hline 7.Sales & 42.2 & 18.7 & 19.3 & 16.6 & 2.0 & 1.1 & 8.6 & 25.4 \\
\hline 8.Process & 69.4 & 9.0 & 6.2 & 5.5 & 2.8 & 7.1 & 11.5 & 17.9 \\
\hline 9.Element & 42.2 & 16.9 & 19.1 & 15.9 & 4.1 & 2.0 & 9.0 & 25.9 \\
\hline Metro. Reg. & 50.1 & 25.4 & 9.7 & 9.5 & 3.3 & 2.0 & 12.3 & 33.0 \\
\hline
\end{tabular}

Data source: Census 2011 (Office for National Statistics, 2016).

${ }^{1}$ Main mode is defined as the longest distance journey stage.

${ }^{2}$ Crow flies mean journey-to-work distance at MSOA scale, home workers removed.

long walking stages, and minimising the number of transit interchanges (Smith, 2018). A second private transport model has also been developed using average road speeds information during the morning peak with average road speed data from Highways England and the Department for Transport. The results of both models have been validated against the Labour Force Survey and online journey planner results (Smith, 2018).

There are several limitations in the travel cost models. Firstly, the models measure travel time, and do not include money costs. This is a significant shortcoming given the importance of transport costs in accessibility inequalities (El-Geneidy et al., 2016). To allow consideration of trip affordability, more affordable travel modes are modelled separately. Bus travel is considerably cheaper than rail travel in the study area, as reflected by approximately three times higher rates of bus travel for the three lowest income occupational classes (6, 7 and 9) shown in Table 3. Green cells in Table 3 show values above metro region averages, and orange cells below metro region averages. The importance of bus connections for low income groups in the UK has been recognised in previous studies (Social Exclusion Unit, 2003). Walking is also around twice as frequent for low income groups. By including additional bus-only and walk-only models, the accessibility of these more affordable modes can be compared to car and rail accessibility in the analysis. Car is the most popular mode in the study area for all occupational classes. Variation in car use correlates inversely with the proportion of jobs in the Inner GLA for each class, and there is an additional income effect as seen in lower car use for classes 7 and 9. Average income correlates with journey-to-work distances, as wealthier groups typically commute further for more specialised jobs, often agglomerated in the inner-city (Smith, 2011). Note that park-and-ride cartransit combinations are not modelled, and cycling has also been omitted (Smith, 2018).

The spatial and temporal resolution of the model is another important consideration. The MSOA scale has been chosen for the model, with 1974 MSOAs in total in the study area, each with approximately 8000 residents. Smaller geographies were found to be problematic computationally (Smith, 2018). Another important aspect in relation to model resolution is the temporal resolution. The private car model is based on average road speeds across the morning peak period. In the public transport model, the results are based on averaging five arrival time queries between 8.30 am and 9.30 am at 15 min intervals (Smith, 2018). 
Table 4

Sub-regional occupational class percentages by residence 2011 .

\begin{tabular}{|c|c|c|c|c|c|c|c|c|c|c|}
\hline & Manag & Prof & $\begin{array}{c}\text { Assoc } \\
\text { Prof }\end{array}$ & Admin & $\begin{array}{l}\text { Skilled } \\
\text { Trades }\end{array}$ & $\begin{array}{l}\text { Other } \\
\text { Serv }\end{array}$ & Sales & Process & Element & Total \\
\hline Inner GLA & 12.4 & 25.3 & 19.4 & 9.8 & 6.3 & 7.2 & 6.7 & 3.4 & 9.4 & 100 \\
\hline Outer GLA & 11.1 & 20.5 & 14.1 & 12.9 & 9.7 & 8.3 & 8.0 & 5.6 & 9.8 & 100 \\
\hline OMA & 12.7 & 18.5 & 14.3 & 12.2 & 10.9 & 8.8 & 7.6 & 5.8 & 9.2 & 100 \\
\hline Metro. Reg. & 12.1 & 20.5 & 15.3 & 11.9 & 9.6 & 8.3 & 7.5 & 5.3 & 9.4 & 100 \\
\hline Great Britain & 10.9 & 17.5 & 12.8 & 11.5 & 11.4 & 9.3 & 8.4 & 7.2 & 11.1 & 100 \\
\hline
\end{tabular}

Data source: Census 2011 (Office for National Statistics, 2016).

\subsection{Group-weighted cumulative accessibility measure}

Cumulative measures have been selected here to provide straightforward comparisons between occupational classes for the four travel modes tested. A key issue with cumulative measures is the selection of travel time thresholds. According to the Labour Force Survey, average travel times to GLA jobs are 36 mins by car, 42 mins bus, 48 mins by underground, and 70 mins by rail (Smith, 2018). Based on average commute times and a sensitivity test of cumulative accessibility results against travel time (Smith, 2018), travel times are tested between 30 and $90 \mathrm{~min}$ at $15 \mathrm{~min}$ intervals. While similar studies have capped times at $60 \mathrm{~min}$ (Owen et al., 2018; Pereira et al., 2018), $90 \mathrm{~min}$ is appropriate here due to relatively longer duration commutes in the regional study area.

A further methodological issue is the method of disaggregating the cumulative location measures by the SOC groups. Locational accessibility results can be weighted by census populations to calculate personweighted residential measures (Anderson et al., 2013). This approach can be extended to weight results by occupational class residential distributions to calculate group-weighted accessibility measures. This method produces an accessibility distribution for each SOC group, which can be analysed in terms of intra-group and inter-group variation using standard statistical techniques.

\section{Occupational class residential geography}

The residential geography of occupational classes will likely be highly influential in the accessibility outcomes. The residential geography of occupational classes is analysed in Section 4.1 using 2011 census data, followed by consideration of dynamics between 2006 and 2016 in Section 4.2 using Annual Population Survey data. Housing tenure is analysed in Section 4.3.

\subsection{Occupational class geography 2011}

The SOC group residential percentage composition for the Inner GLA, Outer GLA and the Outer Metropolitan Area is shown in Table 4. The colours show differences between sub-regional percentages and the metro region average, with green cells having above average sub-regional percentages and orange cells below average sub-regional percentages. While there is a spread of all SOC groups across the sub-regions, there is a clear concentration of more affluent professional classes in the Inner GLA in line with gentrification processes, particularly for the Professional and Associate Professional groups. The most affluent Management group is more evenly dispersed between sub-regions, with an above average concentration in the OMA as well as the Inner GLA. Groups 4-8 have lower than average Inner GLA proportions, in line with higher prices pushing these groups out, although note that the lowest income Elementary group is an exception.

Local residential patterns between SOC groups can be understood by correlating residential populations, as shown in Table 5 at MSOA scale using the same 2011 census data. There is a clear grouping of occupational classes into two super-groups: professional classes and nonprofessional classes. The Administrative class sits between the two super-groups. The correlations show a significant division between where professional and non-professional groups are residentially located.

The professional super-group is mapped in Fig. 2 (note the nonprofessional group is the exact inverse of this map). There is a clear clustering of professional classes in Inner-West London, with two prominent radial corridors extending northwards through Camden, Islington and Hampstead; and south-westwards through Kensington, Wandsworth and Richmond. Concentrations of non-professional groups are mainly in Outer London to the east, north-east and west, with only smaller pockets remaining in Inner London. Segregation also extends beyond the GLA to the OMA, including a significant east-west division, and with richer classes generally favouring smaller OMA towns and villages.

The spatial pattern shown in Fig. 2 points to significant accessibility advantages for professional groups. There are some contradictory aspects to note, including low professional percentages around several major public transport centres such as Stratford and Wembley. Additionally, relationships between accessibility and professional classes appear much weaker in the OMA where more affluent residents often favour more rural settlements with poor public transport.

\subsection{Occupational class dynamics 2006-2016}

The residential dynamics of the occupational classes can be considered by using the Annual Population Survey to describe changes by occupational class over the last decade, at the more aggregate local authority scale. The analysis considers changes between 2006 and $2016,{ }^{2}$ five years before and after the 2011 census data. The percentage point changes in the sub-regional proportions of SOC classes between 2006 and 2016 are shown in Table 6. The colours in the table indicate differences between sub-regional change and the average change for the metro region. Note that a strong professionalization pattern is occurring at the national level as well as in the study area during this period, as shown in the Great Britain row in Table 6. A gentrification pattern is strongly evident in the Inner GLA, with above average gains in all three of the professional classes, particularly for the Management group, and proportional losses for all other classes. Inner-city gentrification has clearly continued in the last decade by this measure. Meanwhile the Outer GLA sub-region has a very different pattern. The Outer GLA has below average increases in the Management and

\footnotetext{
${ }^{2}$ Due to the smaller sample size of the Annual Population Survey (Office for National Statistics, 2018), results are based on three year averages: 2006 results are an average of 2005-2007, and 2016 results are an average of 2015-2017.
} 
Table 5

Pearson Correlation Matrix Between Occupational Classes by Residence 2011, MSOA scale.

\begin{tabular}{|c|c|c|c|c|c|c|c|c|c|}
\hline & Manag & Prof & $\begin{array}{c}\text { Assoc } \\
\text { Prof }\end{array}$ & Admin & $\begin{array}{l}\text { Skilled } \\
\text { Trades }\end{array}$ & $\begin{array}{l}\text { Other } \\
\text { Serv }\end{array}$ & Sales & Process & Element \\
\hline Manag & 1 & $0.76^{* *}$ & $0.79 * *$ & $0.23 * *$ & $-0.26^{* *}$ & $-0.23^{* *}$ & $-0.26 * *$ & $-0.40 * *$ & $-0.38 * *$ \\
\hline Prof & $0.76^{* *}$ & 1 & $0.87^{* *}$ & $0.23 * *$ & $-0.31 * *$ & $-0.16^{* *}$ & $-0.13^{* *}$ & $-0.42 * *$ & $-0.23 * *$ \\
\hline AssocP & $0.79 * *$ & $0.87 * *$ & 1 & $0.36^{* *}$ & $-0.12^{* *}$ & $-0.02 *$ & $-0.05^{*}$ & $-0.28 * *$ & $-0.14 * *$ \\
\hline Admin & $0.23^{* *}$ & $0.23 * *$ & $0.36^{* *}$ & 1 & $0.61^{* *}$ & $0.55^{* *}$ & $0.50 * *$ & $0.39 * *$ & $0.25 * *$ \\
\hline SkilledT & $-0.26 * *$ & $-0.31 * *$ & $-0.12^{* *}$ & $0.61^{* *}$ & 1 & $0.80^{* *}$ & $0.70 * *$ & $0.80 * *$ & $0.66 * *$ \\
\hline OtherS & $-0.23 * *$ & $-0.16^{* *}$ & $-0.02^{*}$ & $0.55^{* *}$ & $0.80 * *$ & 1 & $0.74 * *$ & $0.69 * *$ & $0.70 * *$ \\
\hline Sales & $-0.26^{* *}$ & $-0.13^{* *}$ & $-0.05^{*}$ & $0.50 * *$ & $0.70^{* *}$ & $0.74^{* *}$ & 1 & $0.73^{* *}$ & $0.81 * *$ \\
\hline Process & $-0.40 * *$ & $-0.42 * *$ & $-0.28 * *$ & $0.39 * *$ & $0.80 * *$ & $0.69 * *$ & $0.73 * *$ & 1 & $0.81 * *$ \\
\hline Element & $-0.38 * *$ & $-0.23^{* *}$ & $-0.14^{* *}$ & $0.25 * *$ & $0.66^{* *}$ & $0.70^{* *}$ & $0.81 * *$ & $0.81 * *$ & 1 \\
\hline
\end{tabular}

**Significant at the 0.01 level. *Significant at the 0.05 level

**Significant at the 0.01 level. *Significant at the 0.05 level.

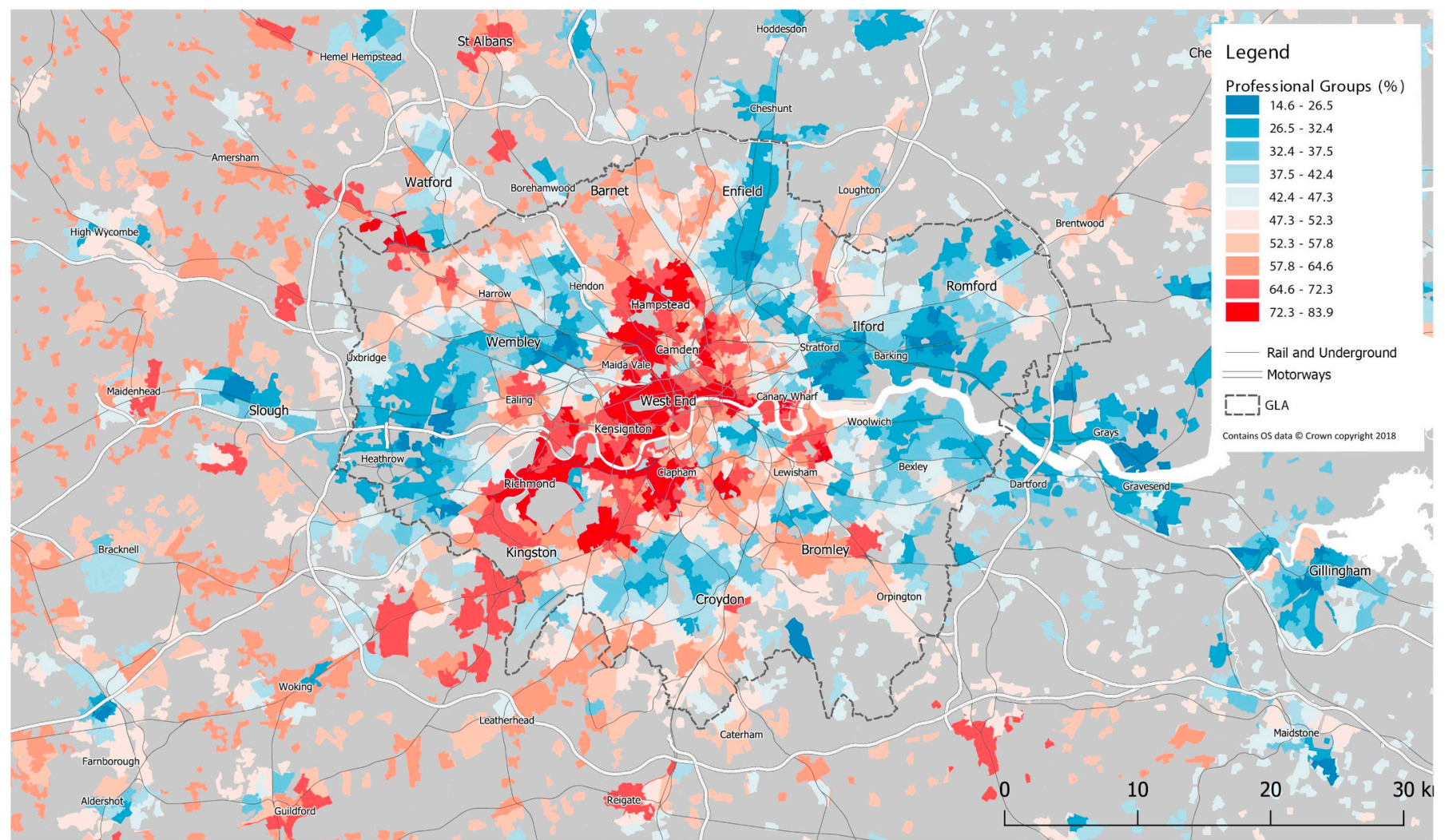

Fig. 2. Professional Classes (Manag., Prof. \& Assoc. Prof.) Residential Percentage 2011. Data: Census 2011 (Office for National Statistics, 2016).

Professional classes, a proportional loss in the Associate Professional class, and gains in the Other Service, Process and Elementary classes. These results confirm recent research identifying the increasing suburbanisation of low income populations in London (Travers et al., 2016). For the OMA sub-region, the overall pattern is more mixed, with above average losses for lower income classes but with below average gains in the two highest income classes.

Further variation within sub-regions can be identified by analysing occupational class dynamics at the local authority level as shown in Fig. 3. Each Local Authority is shown as a trajectory connecting its position in 2006 to its position in 2016 in relation to the percentage of professional classes and the total working population. Generally, Inner GLA boroughs experience high working population growth combined with large increases in the proportion of professional classes. Boroughs with a long history of gentrification, such as Camden and Islington, are higher up in the chart, while more recent gentrifiers, such as Lewisham and Southwark, are rapidly gentrifying from a lower base. Outer GLA boroughs also show substantial population growth but with lower levels of change in professional classes, and decline in some cases. The exceptions are mainly in South and South-West London, with Croydon, Sutton and Richmond all gentrifying. OMA local authorities have a mixed picture, with some increases in professional occupational classes with minimal working population growth; while some lower income towns such as Luton and Harlow are not gentrifying.

\subsection{Housing tenure and occupational class}

The differences in residential geography between occupational 
Table 6

Sub-Regional Occupational Class Percentage Point Change by Residence 2006-2016 (final 2016 sub-regional percentages in brackets).

\begin{tabular}{|c|c|c|c|c|c|c|c|c|c|}
\hline & Manag & Prof & $\begin{array}{l}\text { Assoc } \\
\text { Prof }\end{array}$ & Admin & $\begin{array}{l}\text { Skilled } \\
\text { Trades }\end{array}$ & $\begin{array}{l}\text { Other } \\
\text { Serv }\end{array}$ & Sales & Process & Element \\
\hline \multirow{3}{*}{ Inner GLA } & +2.2 & +3.3 & +0.7 & -3.2 & -1.3 & -0.1 & -0.1 & -0.6 & -0.6 \\
\hline & (13.4) & (27.1) & (20.9) & $(8.2)$ & (5.3) & (6.7) & (6.3) & (3.1) & (8.4) \\
\hline & +0.4 & +2.6 & -0.8 & -4.0 & -0.5 & +1.0 & -0.4 & +0.5 & +1.5 \\
\hline \multirow[t]{2}{*}{ Outer GLA } & $(11.2)$ & (23.4) & (15.1) & $(10.7)$ & (8.9) & (8.2) & (7.1) & (5.4) & (9.7) \\
\hline & +1.2 & +2.2 & +0.6 & -1.7 & -0.5 & +0.9 & -0.7 & -0.7 & -1.1 \\
\hline \multirow[t]{2}{*}{ OMA } & (11.9) & (20.7) & (15.5) & (11.4) & (10.6) & (8.9) & $(7.2)$ & (5.2) & (8.7) \\
\hline & +1.2 & +2.7 & +0.3 & -2.9 & -0.8 & +0.7 & -0.5 & -0.3 & -0.2 \\
\hline Metro. Reg. & $(12.0)$ & (23.1) & $(16.6)$ & $(10.4)$ & (8.8) & $(8.2)$ & (7.0) & (4.8) & (8.9) \\
\hline \multirow{2}{*}{ Grt. Britain. } & +1.0 & +2.6 & +1.1 & -2.4 & -1.2 & +1.0 & -0.8 & -1.0 & -0.4 \\
\hline & $(10.6)$ & (20.3) & (14.4) & $(10.2)$ & (10.3) & (9.2) & (7.5) & (6.3) & (10.7) \\
\hline
\end{tabular}

Data source: Annual Population Survey 2005-2017 (Office for National Statistics, 2018).

classes are embedded in housing market processes, linked to the income inequalities discussed in Section 3.2. While the UK census does not record house prices, housing tenure is recorded which closely relates to affluence, as shown in Table 7. Affluent classes are more likely to own their own home and less likely to rent, in particular through social renting. The three least affluent groups are majority renters in the metro region, and have the highest rates of social renting. Age is also a factor, with the on average older Management, Admin and Process classes more likely to be home owners.

Inner-city housing tenure patterns are particularly important in relation to gentrification. Inner London has seen the biggest price rises in recent decades (Hamnett and Reades, 2019; Travers et al., 2016), translating into wealth benefits for owner occupiers and increased costs for renters. The Inner GLA figures in Table 7 show that the Inner GLA

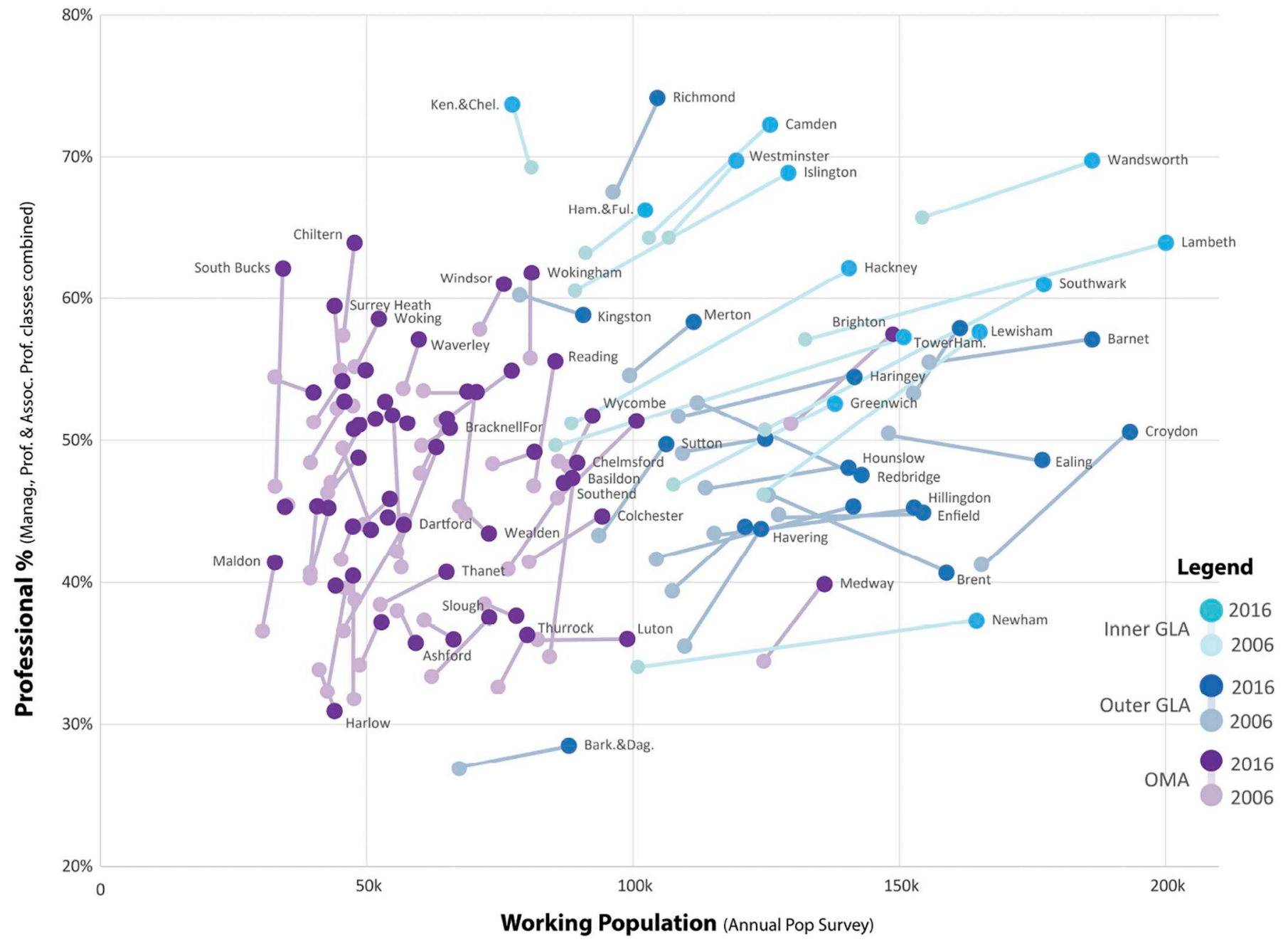

Fig. 3. Local Authority Trajectories for Combined Percentage of Professional Occupational Classes and Total Working Population for 2006 and 2016. Data Source: Annual Population Survey 2005-2017. 
Table 7

Household Housing Tenure by Occupational Class, Metro Region and Inner GLA 2011.

London Metro Region

Inner GLA

\begin{tabular}{lrrrrrrr} 
& $\begin{array}{c}\text { Owner } \\
\text { Occupied }\end{array}$ & \multicolumn{1}{c}{$\begin{array}{c}\text { Private } \\
\text { Renting }\end{array}$} & \multicolumn{1}{c}{$\begin{array}{c}\text { Social } \\
\text { Renting }\end{array}$} & $\begin{array}{c}\text { Owner } \\
\text { Occupied }\end{array}$ & $\begin{array}{c}\text { Private } \\
\text { Renting }\end{array}$ & \multicolumn{1}{c}{$\begin{array}{c}\text { Social } \\
\text { Renting }\end{array}$} \\
\hline Manage & 73.7 & 21 & 5.3 & 54.5 & 35.9 & 9.6 \\
Prof & 69.6 & 24.6 & 5.8 & 51.7 & 37.3 & 11.0 \\
AssoProf & 66.0 & 26.8 & 7.2 & 45.9 & 41.9 & 12.3 \\
Admin & 65.0 & 20.9 & 14.1 & 42.2 & 30.7 & 27.1 \\
Skilled & 63.0 & 22.7 & 14.3 & 37.3 & 33.5 & 29.1 \\
OtherServ & 45.6 & 26.2 & 28.2 & 27.5 & 27.0 & 45.5 \\
Sales & 45.3 & 30.3 & 24.4 & 24.8 & 37.4 & 37.8 \\
Process & 58.5 & 20 & 21.5 & 35.0 & 23.3 & 41.8 \\
Element & 39.2 & 31.4 & 29.4 & 20.7 & 36.6 & 42.7 \\
\hline & & & & & & \\
All & 62.5 & 24.5 & 13.0 & 42.7 & 35.6 & 21.7
\end{tabular}

Data source: Census 2011 (Office for National Statistics, 2016).

owner occupation rate is a full twenty percentage points below the metro region average of $63 \%$. Yet the division between occupational classes is just as strong in the Inner GLA, with professional classes at 46-55\% inner-city owner occupation and the lowest income classes at $21-28 \%$. This pattern is in line with the housing wealth inequalities identified in gentrification research.

In London, inequalities in owner occupation are offset by the social renting sector, particularly in Inner London, which can protect households to a degree from price increases. Inner GLA social renting comprises $38-46 \%$ of households for the four lowest income classes, and it remains the most prevalent inner-city tenure for these groups despite declining supply in recent decades (Watt, 2009).

\section{Accessibility analysis results}

The significant differences in residential location patterns between occupational classes identified in Section 4 will likely translate into employment accessibility differences. The accessibility results are first presented as aggregate measures in Section 5.1 to provide an overview of the broad accessibility geography of the study area. Next the detailed disaggregate results for the occupational classes are provided in Section 5.2. Finally, these results are discussed in relation to housing tenure in Section 5.3 .

\subsection{Accessibility results sub-regional overview}

Sub-regional accessibility differences between Inner London, Outer London and the OMA are likely to be the main driver of accessibility inequalities. These differences can be seen when mapping cumulative accessibility to employment by Public Transport in Fig. 3 (includes rail, underground and bus multi-modal trips), and Fig. 3B by Car, both for 60 min' travel. High inner-city public transport accessibility quickly tails off in Outer London and the OMA. Car accessibility is far more dispersed across Outer London and OMA motorways, particularly to the north and west.

The accessibility distributions for sub-regional working populations are plotted in Fig. 4, with a clear modal hierarchy favouring car travel, and variable competitiveness of public transport between sub-regions. The Inner GLA has the highest accessibility for all modes, with public transport accessibility very competitive with car travel. The Outer GLA has greater variation in car and public transport accessibility, and much poorer bus and walk accessibility. The OMA has very poor public transport and bus accessibility for $60 \mathrm{~min}$ ' travel, and much greater accessibility advantages for the car. The sub-regional analysis is repeated for a 90mins threshold in Fig. 4B. Absolute values increase (note $\mathrm{y}$-axis change) and PT accessibility more than doubles in much of Outer London and some rail-connected OMA areas, leading to a much wider range of OMA results. Bus accessibility also improves considerably in the GLA. Overall, these results indicate a series of accessibility interrelationships with travel mode, sub-region and time threshold, generally favouring inner-city and GLA residents compared to OMA residents.

\subsection{Cumulative employment accessibility results by SOC groups 2011}

The results are presented firstly for residents of the whole metropolitan region, then for GLA residents, both at $60 \mathrm{~min}$ ' travel time. Then the full range of travel times are analysed. Cumulative accessibility results for the metro region at 60mins travel is plotted in Fig. 5A. The first clear result is that variation within groups is high. This follows the earlier residential analysis showing that, despite important differences, all SOC groups are present in all sub-regions. The high intragroup variation is combined with considerable differences in median accessibilities between groups. Differences between groups can be shown more clearly by plotting percentage differences between mean/ median SOC accessibilities and the mean/median for the entire working population averages, as shown in Fig. 5A and B. Note that the means and medians are mode specific, so that the absolute mode differences in Fig. 5A are normalised in $5 \mathrm{~B}$ and $5 \mathrm{C}$.

There is a clear pattern with accessibility advantages for the innercity focussed Professional and Associate Professional groups, and below average accessibility for SOC groups 4 to 8 . Percentage differences between means are highest for the more local bus and walk modes; while the median results emphasise larger percentage differences in public transport accessibility. While the accessibility advantages for professional classes match the expected impacts of gentrification, it is surprising that the highest and lowest income SOC groups have close to average results. The Management group is influenced by a high 

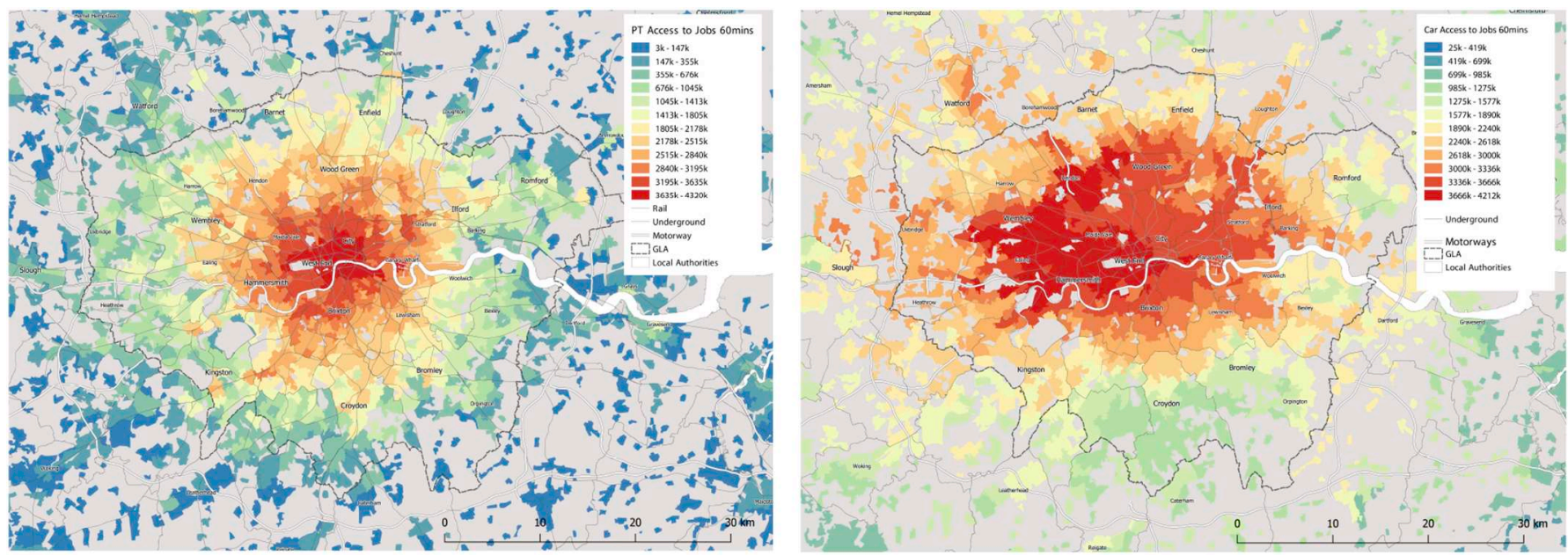

Fig. 3. A \&B Cumulative employment accessibility maps GLA, 60mins by Public Transport (left) and by 60mins by Car (right).

proportion of low accessibility OMA residents (this is confirmed in the GLA results). The Elementary group is discussed in Section 5.3. There are two groups with consistently below average accessibility: Skilled Trades and Process. Both these groups are highly car oriented (see earlier Table 3) with employment geographies focussed outside the inner-city. Arguably it is the Other Service and Sales groups that are the most accessibility disadvantaged in the study area, as these groups are frequent bus and walk commuters despite lower accessibility for these modes.

A key research question is the consistency of the SOC accessibility differences across sub-regions and travel times. The $60 \mathrm{~min}$ analysis is repeated for GLA residents in Fig. 6. The urban GLA has considerably higher accessibilities for all modes as shown in Fig. 6A, with a narrowing of distributions for car and public transport accessibilities, but not for the bus mode. The same general pattern between SOC groups is evident, with advantages for professional groups and disadvantages for groups 4-8. Note that the Management group now matches the advantages of other professional groups after the removal of OMA residents. The overall pattern of percentage differences in means is consistent with the metropolitan region, but at lower percentages for public transport and bus modes. Median percentage differences on the other hand are much higher for the bus mode for the GLA rather than public transport.

The influence of travel time threshold on the accessibility results are shown in Tables 8-13, with times between 30 and 90 min tested at 15 min intervals. The tables are presented in the same order as the previous analysis, with absolute results shown for each mode for the metro region in Table 8 and for the GLA in Table 11, followed by percentage differences in means and medians between SOC groups, here for the public transport and bus modes only. Car and walk modes are omitted as car accessibilities were found to be relatively equitable across all travel times, while walk accessibility show consistent differences for all travel times. There are very large differences (i.e. doubling or more) in absolute accessibilities between 30 and $45 \mathrm{~min}$, and 45 and $60 \mathrm{~min}$, both for the metro region and the GLA, similar to findings in comparable studies (Owen et al., 2018). This confirms the importance of individual travel time budgets on accessibility inequalities.

The percentage differences in means and medians between SOC groups for public transport and bus modes have the same general structure for all travel times, with consistent advantages for professional groups, and disadvantages for groups 4-8. Percentage difference in SOC means fall as travel times increase, as do the standard deviations, as more residents can overcome spatial differences at longer travel times. The percentage differences in median values show much more variability, and there are key thresholds where median differences between SOC groups are highest. Public transport medians show high variability at $60 \mathrm{~min}$ in the metro region, and $45 \mathrm{~min}$ in the GLA. Bus medians have highest variability at 75 and $90 \mathrm{~min}$ in the metro region, and at 60 min in the GLA. High variability in medians occurs at points where approximately $50 \%$ of professional populations can reach major employment centres, compared to other SOC groups where the majority of residents are not able to reach these centres. These results are in line with professional groups securing housing with $45-60 \mathrm{~min}$ ' rail and metro access to major employment centres.
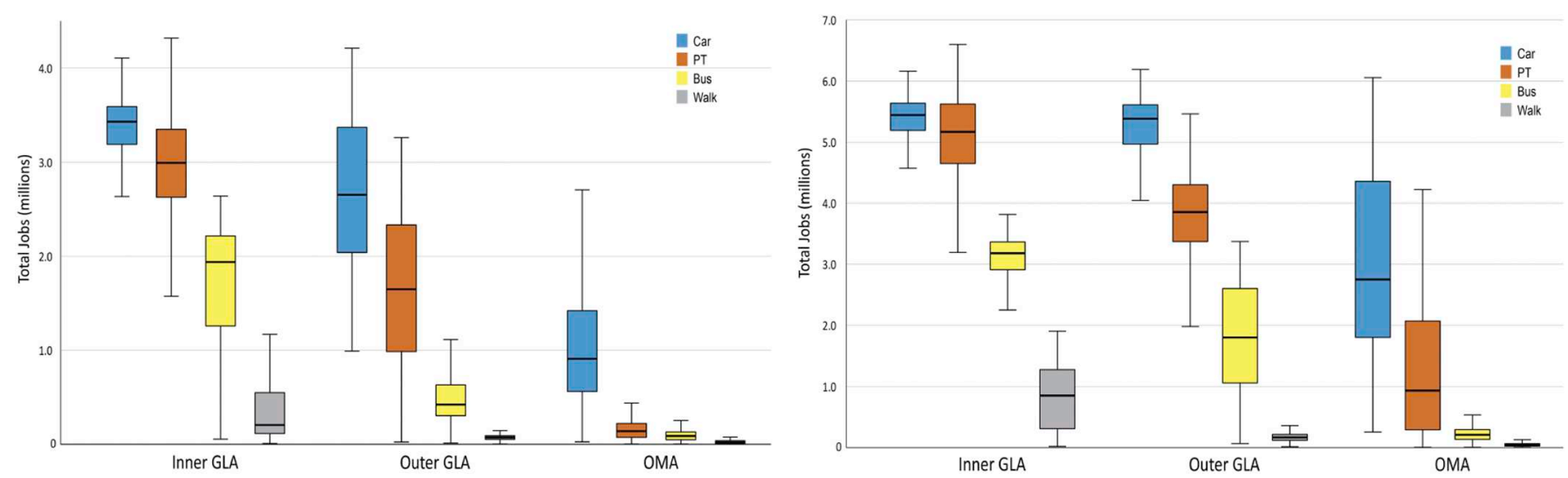

Fig. 4. A \& B Boxplots of Car, PT, Bus \& Walk Working Population Cumulative Employment Accessibility by Sub-Regions for 60mins Travel (left); and 90mins Travel (right). 

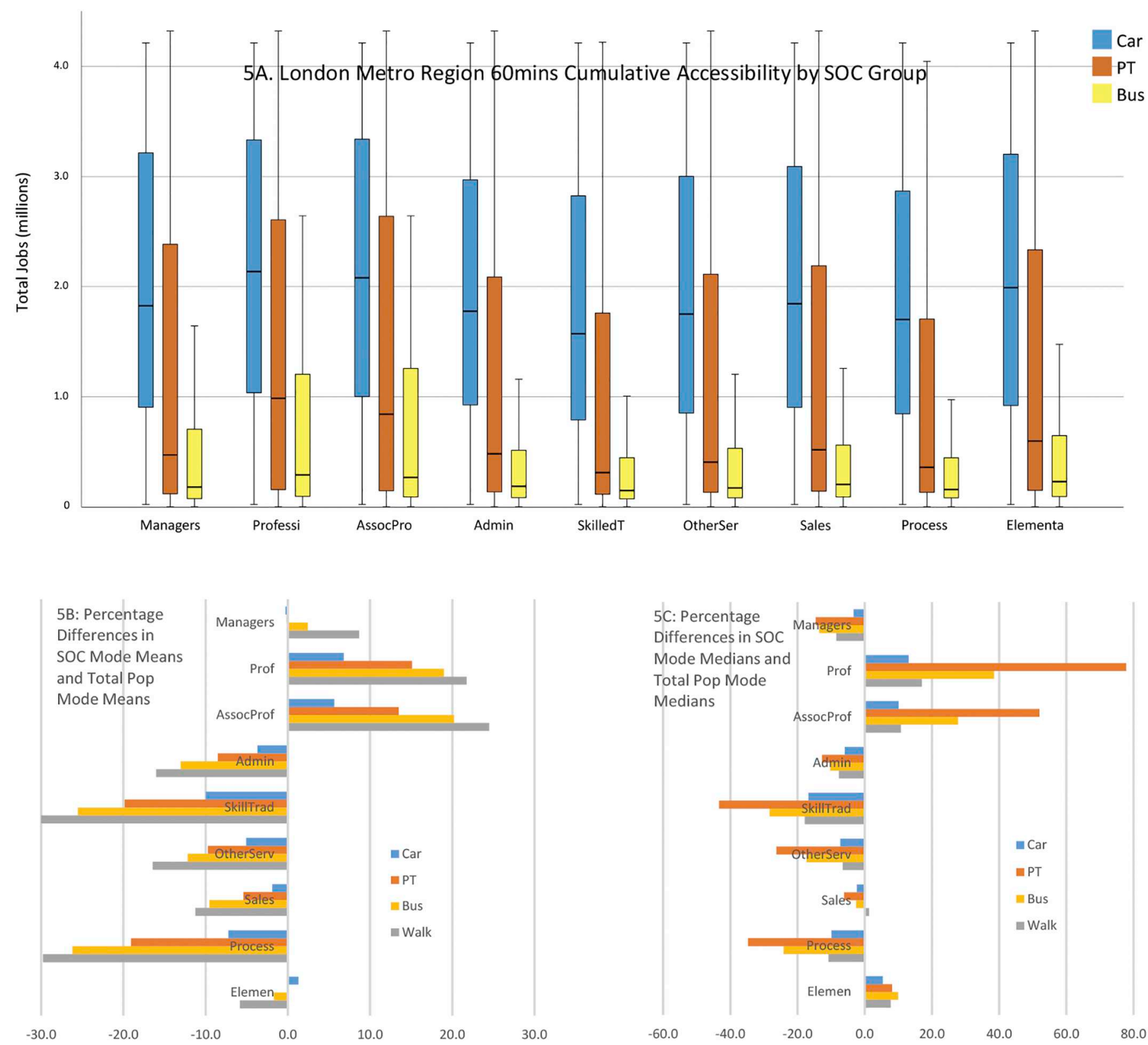

Fig. 5. A, B \& C: London Metro Region 60mins Cumulative Accessibility to Employment by SOC Groups: Absolute Results (top); Percentage Differences in SOC Mode Means from Overall Mode Means (bottom left); Percentage Differences in SOC Mode Medians from Overall Mode Medians (bottom right).

\subsection{Accessibility and housing tenure}

The housing tenure variation identified in Section 4.3 adds an important perspective to the accessibility results. Accessibility advantages for professional groups are combined with much higher rates of owner occupation, and therefore represent both direct accessibility benefits to jobs, and, for home owners, probable housing wealth benefits as more accessible inner-city locations have experienced the highest price rises (Hamnett and Reades, 2019; Travers et al., 2016). In contrast, the lower income groups are less likely to live in more accessible public transport locations, and are less likely to own homes when they do. The accessibility results for the lowest income Elementary group are close to the overall average, which is a positive result, linked to the marginally higher inner-city concentration of this group (Table 4). The tenure data does however provide a less positive perspective, given the low rates of owner occupation for this group, and therefore greater vulnerability to rent increases. Social renting is the most prevalent inner-city tenure for the four lowest income classes, and given continuing price and rent rises, is crucial in maintaining a diverse mix of occupational classes in Inner London.

The low accessibility results are for the Skilled Trades and Process groups are linked to more car-dependent occupations mainly based outside of Inner London. These groups do have relatively high levels of owner occupation, and appear to have prioritised housing security over public transport accessibility.

\subsection{Methodology limitations}

There are several methodological limitations in this study that future work can consider. Generalised cost analysis, including accurate transit fares and parking costs, would be a significant improvement. Additional measures could consider accessibility outside of the morning peak, unemployed groups, gender differences and part-time workers. Generational differences are also important, particularly in relation to 

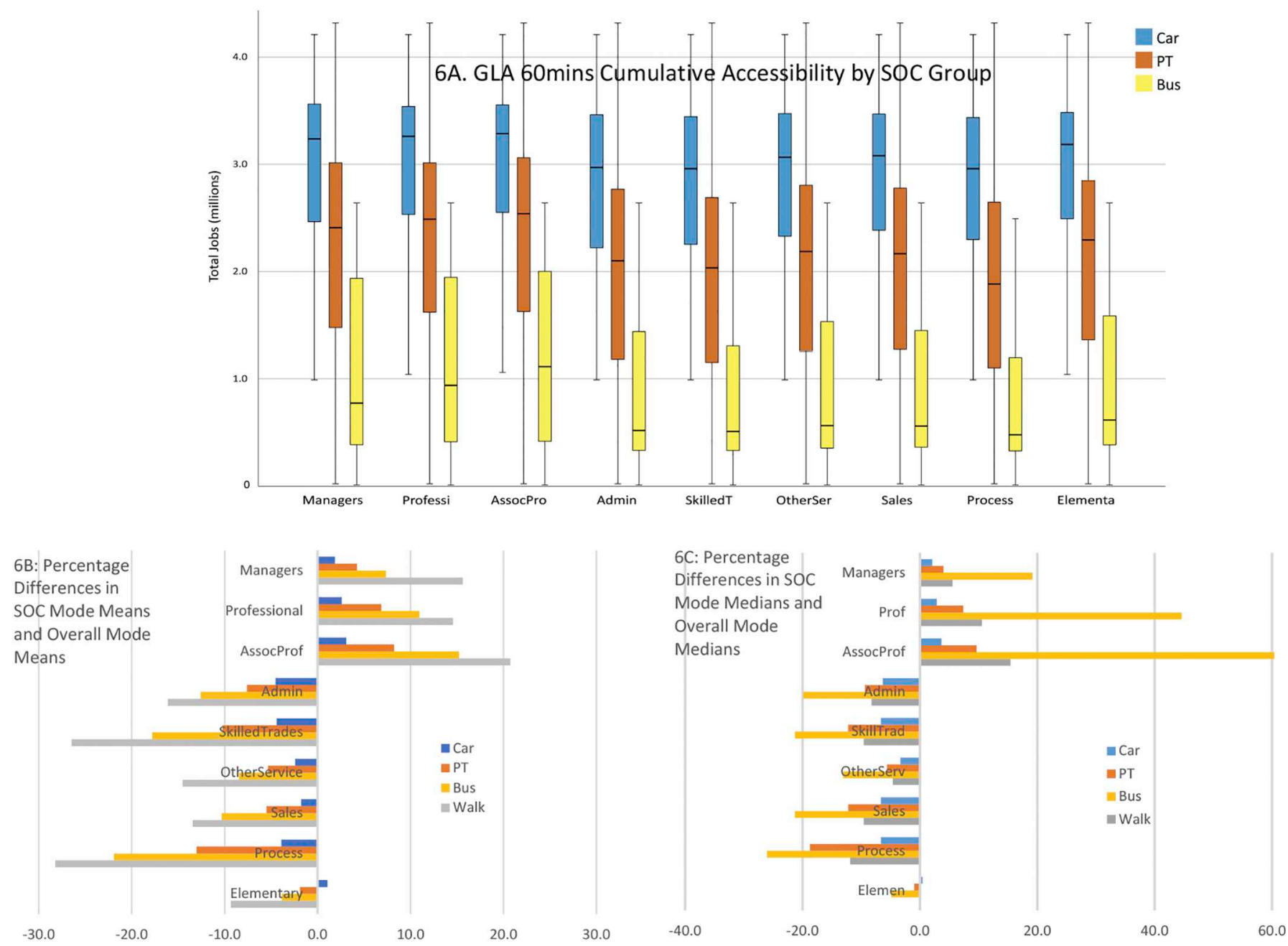

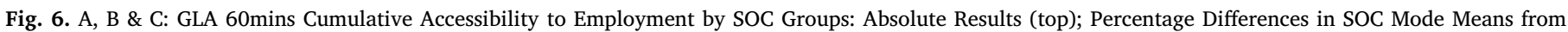
Overall Mode Means (bottom left); Percentage Differences in SOC Mode Medians from Overall Mode Medians (bottom right).

housing inequalities. Disaggregating employment opportunities would also be useful, and would likely show further professional advantages connected to inner-city agglomerations.

\section{Conclusions}

\subsection{Accessibility inequalities between SOC groups}

This research has found employment accessibility inequalities between Standard Occupational Classification (SOC) groups in the London Metropolitan Region, with advantages for inner-city focussed Professional and Associate Professional groups and disadvantages for SOC groups 4-8. This pattern is broadly in line with studies of Paris (Korsu and Wenglenski, 2010) and the San Francisco Bay Area (Cervero et al., 1999), which found employment accessibility advantages for more affluent populations. Inequalities in the London Metropolitan Region were found in public transport, bus and walking modes, while car accessibility is much more evenly distributed between groups (although parking costs were not modelled). The general pattern of accessibility advantages for inner-city focussed professional groups is consistent across a range of travel times, while the magnitude of the differences between groups varies by travel time. Median accessibility differences in public transport accessibility were greatest at 45 and $60 \mathrm{~min}$. This reflects the greater ability of professional classes to secure housing with transit connections to major employments centres within typical commute times.

Further to the broad accessibility differences identified, additional patterns were found for particular SOC groups. The greatest advantages were for the Professional and Associate professional classes, while advantages for the Management class were offset by a greater preference

Table 8

Metro region absolute results table for working population (units: thousands of jobs).

\begin{tabular}{|c|c|c|c|c|c|c|c|c|c|c|c|c|c|c|c|}
\hline & \multicolumn{3}{|c|}{30 mins } & \multicolumn{3}{|l|}{45 mins } & \multicolumn{3}{|l|}{60 mins } & \multicolumn{3}{|l|}{75 mins } & \multicolumn{3}{|l|}{90 mins } \\
\hline & Mean & Median & StDev. & Mean & Median & StDev. & Mean & Median & StDev. & Mean & Median & StDev. & Mean & Median & StDev. \\
\hline Car & 439.6 & 291.5 & 417.2 & 1094.6 & 828.0 & 801.7 & 2007.6 & 1887.7 & 1172.3 & 3083.1 & 3572.4 & 1474.2 & 4200.6 & 4949.7 & 1628.6 \\
\hline PT & 133.3 & 54.5 & 243.1 & 532.6 & 169.1 & 713.8 & 1193.5 & 554.5 & 1212.6 & 1960.6 & 1870.2 & 1603.1 & 2810.0 & 3051.2 & 1848.3 \\
\hline Bus & 90.2 & 43.2 & 169.9 & 278.0 & 107.4 & 420.0 & 566.3 & 211.3 & 715.2 & 917.0 & 389.9 & 997.3 & 1299.3 & 652.3 & 1241.2 \\
\hline Walk & 25.2 & 12.0 & 58.5 & 59.3 & 28.8 & 123.9 & 110.7 & 49.6 & 211.5 & 175.6 & 71.3 & 306.3 & 254.3 & 97.6 & 407.4 \\
\hline
\end{tabular}


Table 9

Metro region public transport percentage differences for SOC groups from all working population.

\begin{tabular}{|c|c|c|c|c|c|c|c|c|c|c|c|c|c|c|c|}
\hline & \multicolumn{3}{|l|}{30 mins } & \multicolumn{3}{|c|}{45 mins } & \multicolumn{3}{|c|}{60 mins } & \multicolumn{3}{|c|}{75 mins } & \multicolumn{3}{|l|}{90 mins } \\
\hline & Mean & Median & StDev. & Mean & Median & StDev. & Mean & Median & StDev. & Mean & Median & StDev. & Mean & Median & StDev. \\
\hline Manag & 6.4 & -8.1 & 8.6 & 2.4 & -12.0 & 4.5 & -0.2 & -14.6 & 3.5 & -1.2 & -8.3 & 3.6 & -1.8 & -3.1 & 4.2 \\
\hline Prof & 22.1 & 19.0 & 14.8 & 19.9 & 37.4 & 9.0 & 15.1 & 77.8 & 5.0 & 11.5 & 31.7 & 3.2 & 8.7 & 12.6 & 2.3 \\
\hline AssocProf & 24.2 & 14.5 & 16.0 & 20.6 & 23.2 & 10.8 & 13.5 & 52.0 & 6.6 & 9.5 & 25.7 & 4.8 & 7.0 & 9.3 & 4.2 \\
\hline Admin & -15.3 & -8.8 & 12.3 & -13.6 & -11.3 & 8.7 & -8.5 & -12.7 & 5.8 & -5.5 & -9.1 & 4.6 & -3.8 & -3.5 & 4.4 \\
\hline SkillTrad & -30.6 & -19.8 & 26.9 & -26.5 & -29.8 & 17.6 & -19.8 & -43.3 & 10.4 & -15.7 & -36.1 & 7.0 & -12.5 & -15.8 & 4.8 \\
\hline OtherServ & -16.3 & -8.3 & 15.0 & -13.2 & -16.7 & 8.6 & -9.7 & -26.3 & 5.3 & -7.4 & -15.0 & 3.6 & -5.7 & -6.5 & 2.8 \\
\hline Sales & -11.4 & 0.6 & 11.7 & -9.8 & -4.2 & 8.1 & -5.4 & -6.1 & 5.1 & -3.1 & -3.2 & 4.1 & -1.9 & -1.8 & 4.2 \\
\hline Process & -30.0 & -13.4 & 27.7 & -27.1 & -23.8 & 19.6 & -19.1 & -34.7 & 12.4 & -13.4 & -24.8 & 9.3 & -9.3 & -11.2 & 8.6 \\
\hline Element & -4.9 & 6.5 & 8.2 & -1.2 & 6.2 & 3.7 & 0.0 & 8.2 & 2.5 & 0.6 & 4.8 & 2.5 & 1.2 & 1.7 & 3.0 \\
\hline
\end{tabular}

Table 10

Metro Region Bus Percentage Differences for SOC Groups from All Working Population.

\begin{tabular}{|c|c|c|c|c|c|c|c|c|c|c|c|c|c|c|c|}
\hline & \multicolumn{3}{|c|}{30 mins } & \multicolumn{3}{|c|}{45 mins } & \multicolumn{3}{|c|}{60 mins } & \multicolumn{3}{|l|}{75 mins } & \multicolumn{3}{|l|}{90 mins } \\
\hline & Mean & Median & StDev. & Mean & Median & StDev. & Mean & Median & StDev. & Mean & Median & StDev. & Mean & Median & StDev. \\
\hline Manag & 7.4 & -7.5 & 9.7 & 3.9 & -7.5 & 5.5 & 2.4 & -13.6 & 4.4 & 0.8 & -11.0 & 3.4 & -0.5 & -11.5 & 3.0 \\
\hline Prof & 21.4 & 16.6 & 16.4 & 20.2 & 27.2 & 11.2 & 19.0 & 38.5 & 8.7 & 16.5 & 41.4 & 6.5 & 13.7 & 55.0 & 4.5 \\
\hline AssocProf & 23.7 & 11.0 & 17.4 & 23.0 & 18.1 & 13.8 & 20.2 & 27.7 & 11.1 & 16.0 & 32.4 & 8.2 & 12.3 & 36.3 & 5.9 \\
\hline Admin & -15.1 & -8.6 & 13.3 & -14.5 & -7.5 & 10.6 & -13.0 & -10.3 & 8.8 & -10.6 & -9.1 & 6.9 & -7.9 & -10.4 & 5.3 \\
\hline SkillTrad & -29.9 & -19.6 & 29.0 & -28.6 & -20.9 & 22.4 & -25.6 & -28.3 & 17.5 & -21.8 & -37.2 & 12.9 & -18.4 & -36.9 & 9.3 \\
\hline OtherServ & -16.0 & -6.7 & 16.6 & -13.8 & -10.3 & 10.4 & -12.2 & -17.3 & 7.9 & -10.1 & -19.0 & 5.8 & -8.2 & -19.0 & 4.1 \\
\hline Sales & -11.0 & 0.2 & 12.7 & -10.3 & 0.4 & 9.3 & -9.5 & -2.6 & 8.2 & -7.2 & -2.6 & 6.5 & -4.7 & -2.7 & 4.8 \\
\hline Process & -28.8 & -12.3 & 29.9 & -28.3 & -15.6 & 23.5 & -26.2 & -24.2 & 20.1 & -22.0 & -27.7 & 15.6 & -17.5 & -28.9 & 11.5 \\
\hline Element & -6.0 & 4.7 & 10.4 & -2.6 & 6.6 & 4.5 & -1.7 & 9.9 & 3.7 & -0.5 & 6.3 & 2.9 & 0.4 & 10.6 & 2.2 \\
\hline
\end{tabular}

Table 11

GLA Absolute Results Table for Working Population (units: thousands of jobs).

\begin{tabular}{|c|c|c|c|c|c|c|c|c|c|c|c|c|c|c|c|}
\hline & \multicolumn{3}{|c|}{30 mins } & \multicolumn{3}{|l|}{45 mins } & \multicolumn{3}{|l|}{60 mins } & \multicolumn{3}{|l|}{75 mins } & \multicolumn{3}{|l|}{90 mins } \\
\hline & Mean & Median & StDev. & Mean & Median & StDev. & Mean & Median & StDev. & Mean & Median & StDev. & Mean & Median & StDev. \\
\hline Car & 666.0 & 481.0 & 476.9 & 1647.0 & 1651.8 & 747.0 & 2927.0 & 3170.9 & 769.2 & 4239.5 & 4347.9 & 585.3 & 5353.0 & 5404.7 & 397.3 \\
\hline PT & 234.8 & 113.9 & 308.2 & 979.6 & 668.1 & 772.2 & 2160.6 & 2317.0 & 971.0 & 3319.2 & 3349.6 & 950.1 & 4328.1 & 4330.1 & 964.7 \\
\hline Bus & 153.7 & 77.5 & 219.6 & 497.4 & 256.9 & 498.8 & 1024.7 & 649.5 & 760.6 & 1655.5 & 1674.5 & 918.2 & 2318.0 & 2606.5 & 943.1 \\
\hline Walk & 41.0 & 20.6 & 78.4 & 101.0 & 49.8 & 162.7 & 193.5 & 90.5 & 271.7 & 311.5 & 146.8 & 383.0 & 456.2 & 220.3 & 493.3 \\
\hline
\end{tabular}

Table 12

GLA Public Transport Percentage Differences for SOC Groups from All Working Population.

\begin{tabular}{|c|c|c|c|c|c|c|c|c|c|c|c|c|c|c|c|}
\hline & \multicolumn{3}{|l|}{30 mins } & \multicolumn{3}{|c|}{45 mins } & \multicolumn{3}{|c|}{60 mins } & \multicolumn{3}{|c|}{75 mins } & \multicolumn{3}{|c|}{90 mins } \\
\hline & Mean & Median & StDev. & Mean & Median & StDev. & Mean & Median & StDev. & Mean & Median & StDev. & Mean & Median & StDev. \\
\hline Manag & 12.4 & 6.4 & 9.5 & 7.3 & 18.4 & 4.1 & 4.2 & 4.0 & 2.4 & 3.0 & 2.1 & 2.3 & 2.3 & 2.1 & 2.3 \\
\hline Prof & 14.7 & 10.0 & 9.7 & 11.3 & 37.4 & 2.6 & 6.8 & 7.4 & 2.2 & 4.5 & 3.2 & 3.1 & 3.5 & 3.2 & 2.5 \\
\hline AssocProf & 20.2 & 14.2 & 11.1 & 15.2 & 53.9 & 3.9 & 8.2 & 9.6 & 0.3 & 5.3 & 5.4 & 0.4 & 4.3 & 4.9 & 0.1 \\
\hline Admin & -15.3 & -11.2 & 10.4 & -12.9 & -26.4 & 4.3 & -7.6 & -9.4 & 0.2 & -4.9 & -5.5 & 0.6 & -3.9 & -5.3 & 0.1 \\
\hline SkillTrad & -25.2 & -13.0 & 21.5 & -18.1 & -28.8 & 10.2 & -10.2 & -12.2 & 3.0 & -6.9 & -6.5 & 2.5 & -5.5 & -6.1 & 3.3 \\
\hline OtherServ & -14.0 & -6.7 & 12.3 & -9.3 & -17.6 & 4.7 & -5.3 & -5.6 & 1.6 & -3.5 & -3.9 & 1.3 & -2.8 & -3.8 & 1.8 \\
\hline Sales & -13.1 & -8.0 & 10.6 & -10.3 & -18.5 & 5.5 & -5.5 & -6.5 & 2.6 & -3.5 & -3.9 & 2.7 & -2.8 & -4.0 & 2.9 \\
\hline Process & -27.8 & -15.2 & 23.0 & -22.2 & -35.3 & 12.1 & -13.0 & -18.7 & 3.6 & -8.5 & -8.6 & 2.7 & -6.7 & -7.5 & 4.1 \\
\hline Element & -7.9 & -1.5 & 8.6 & -3.3 & -3.1 & 4.3 & -1.9 & -1.0 & 3.4 & -1.4 & -1.2 & 3.4 & -1.0 & -1.3 & 3.5 \\
\hline
\end{tabular}

for residences in the wider region. The lowest accessibility results were for the car-oriented Skilled Trades and Process SOC groups. A positive accessibility equity finding was that the lowest income Elementary group has average accessibility levels, reflecting a relatively high proportion of inner-city residents for this group.

Bus and walking modes were modelled independently to measure accessibility by more affordable travel modes. Accessibility by these more affordable modes is generally low in absolute terms outside of Inner London, and is particularly poor in the OMA. For the bus mode, less than half the number of jobs are reachable at typical commute times compared to the full public transport network. Furthermore, professional classes showed consistently higher bus and walking accessibility than lower income classes. Given that lower income groups are the most frequent bus and walking commuters, and that these classes are increasingly being priced out of Inner London, these limitations are a significant accessibility challenge for London.

\subsection{Accessibility and housing}

The anticipated close connections between residential location 
Table 13

GLA bus percentage differences for SOC groups from all working population.

\begin{tabular}{|c|c|c|c|c|c|c|c|c|c|c|c|c|c|c|c|}
\hline & \multicolumn{3}{|c|}{30 mins } & \multicolumn{3}{|c|}{45 mins } & \multicolumn{3}{|c|}{60 mins } & \multicolumn{3}{|c|}{75 mins } & \multicolumn{3}{|c|}{90 mins } \\
\hline & Mean & Median & StDev. & Mean & Median & StDev. & Mean & Median & StDev. & Mean & Median & StDev. & Mean & Median & StDev. \\
\hline Manag & 14.1 & 4.4 & 10.6 & 9.3 & 8.0 & 5.4 & 7.4 & 19.2 & 3.3 & 5.3 & 7.3 & 1.6 & 3.8 & 4.1 & 0.9 \\
\hline Prof & 14.9 & 7.3 & 11.4 & 12.5 & 11.7 & 5.6 & 11.0 & 44.6 & 2.1 & 8.6 & 17.7 & 1.0 & 6.2 & 6.1 & 3.8 \\
\hline AssocProf & 20.6 & 10.0 & 12.8 & 18.4 & 19.9 & 7.8 & 15.2 & 71.5 & 3.8 & 11.0 & 28.6 & 0.3 & 7.4 & 8.1 & 1.9 \\
\hline Admin & -15.6 & -8.5 & 11.7 & -14.3 & -12.4 & 7.7 & -12.6 & -19.8 & 4.2 & -10.0 & -18.6 & 0.6 & -7.3 & -11.7 & 2.5 \\
\hline SkillTrad & -25.8 & -10.1 & 24.0 & -22.1 & -14.0 & 15.9 & -17.8 & -21.3 & 10.0 & -13.2 & -20.4 & 4.4 & -9.4 & -14.7 & 0.0 \\
\hline OtherServ & -14.6 & -5.7 & 14.1 & -10.7 & -8.2 & 7.1 & -8.5 & -13.1 & 3.9 & -6.1 & -11.5 & 1.6 & -4.1 & -5.9 & 0.1 \\
\hline Sales & -13.4 & -5.4 & 11.9 & -11.5 & -8.3 & 7.4 & -10.3 & -13.7 & 5.4 & -7.6 & -14.1 & 3.3 & -5.0 & -8.6 & 2.0 \\
\hline Process & -28.0 & -12.7 & 25.7 & -25.0 & -16.8 & 17.5 & -21.9 & -26.1 & 12.5 & -16.9 & -32.6 & 6.5 & -12.0 & -19.2 & 1.3 \\
\hline Element & -9.6 & 0.0 & 10.9 & -5.1 & -0.1 & 4.5 & -3.8 & -4.9 & 3.9 & -2.4 & -3.0 & 3.5 & -1.4 & -2.9 & 3.7 \\
\hline
\end{tabular}

patterns and accessibility are strongly borne out in the results, with the proportion of inner-city residents for each SOC group closely related to average employment accessibility. The highest accessibility professional classes are most prevalent in Inner London, and furthermore this concentration is increasing over time. The analysis of SOC changes between 2006 and 2016 demonstrates a continuing gentrification dynamic for the inner-city and contrasting proportional increase in lower income groups in Outer London. These findings indicate the long term trend of growth in professional and managerial classes in Inner London is continuing (Hamnett, 2015). This trend will exacerbate the accessibility inequalities identified, with lower income residents priced out of more accessible locations, reducing opportunities for more affordable commutes and likely increasing travel costs.

Housing tenure data for the SOC groups was also analysed. Professional groups combine accessibility advantages with the highest rates of owner occupation, thus are able to maximise wealth gains in addition to receiving more direct accessibility benefits. Lower income groups are less likely to live in transit accessible locations, and less likely to own houses when they do. Social renting is the most frequent tenure for lower income classes in Inner London. Despite decades of decline in London's social housing stock, it remains a vital sector for buffering lower income groups from gentrification pressures in Inner London.

\subsection{Policy implications}

In terms of transport policy, this research supports efforts to improve the affordability and connectivity of public transport for lower income populations. This is indeed a priority of the current London Mayor, who has committed to freezing public transport fares, and has reformed ticketing to allow multiple bus journeys on a single fare (Khan, 2016). Note these measures are of limited help to residents outside of the GLA, where privatisation has seen higher fares on both rail and bus networks.

The main policy conclusion is the importance of housing policy in influencing accessibility outcomes in the study area. Low and moderate income groups are being priced out of public transport accessible areas. Without a step-change in the delivery of genuinely affordable housing in accessible locations, the increasing dominance of Inner London by professional classes will continue, resulting in greater accessibility inequalities, and likely increased travel costs for lower income classes.

\section{Declaration of Competing Interest}

None.

\section{Acknowledgements}

This research was funded by the Economic and Social Research Council RESOLUTION grant, reference ES/N011449/1.

\section{References}

Alonso, W., 1964. Location and Land Use. Harvard University Press, Cambridge, Mass. Anas, A., Arnott, R., Small, K.A., 1998. Urban Spatial Structure. J. Econ. Lit. 36, 1426-1464.

Anderson, P., Levinson, D., Parthasarathi, P., 2013. Accessibility futures. Trans. GIS 17, $683-705$.

Benenson, I., Martens, K., Rofé, Y., Kwartler, A., 2011. Public transport versus private car GIS-based estimation of accessibility applied to the Tel Aviv metropolitan area. Ann. Reg. Sci. 47, 499-515.

Boisjoly, G., El-Geneidy, A.M., 2017. How to get there? A critical assessment of accessibility objectives and indicators in metropolitan transportation plans. Transp. Policy 55, 38-50. https://doi.org/10.1016/j.tranpol.2016.12.011.

Bueno Cadena, P.C., Vassallo Magro, J.M., Herraiz Tabernero, I., Loro Aguayo, M., 2016. Social and distributional effects of public transport fares and subsidy policies: case of Madrid. Transp. Res. Rec. J. Transp. Res. Board 47-54.

Cervero, R., 2001. Efficient urbanisation: economic performance and the shape of the Metropolis. Urban Stud. 38, 1651-1671. https://doi.org/10.1080/ 00420980120084804.

Cervero, R., Rood, T., Appleyard, B., 1999. Tracking accessibility: employment and housing opportunities in the San Francisco Bay Area. Environ. Plan. A 31, 1259-1278.

Church, A., Frost, M., Sullivan, K., 2000. Transport and social exclusion in London. Transp. Policy 7, 195-205.

Davidson, M., Lees, L., 2005. New-build 'gentrification' and London's Riverside renaissance. Environ. Plan. Econ. Space 37, 1165-1190. https://doi.org/10.1068/ a3739.

Davidson, M., Lees, L., 2010. New-build gentrification: its histories, trajectories, and critical geographies. Popul. Space Place 16, 395-411. https://doi.org/10.1002/psp. 584.

Ehrenhalt, A., 2012. The Great Inversion and the Future of the American City. Vintage, New York.

El-Geneidy, A., Levinson, D., Diab, E., Boisjoly, G., Verbich, D., Loong, C., 2016. The cost of equity: assessing transit accessibility and social disparity using total travel cost. Transp. Res. Part Policy Pract. 91, 302-316.

Elias, P., Birch, M., 2010. SOC2010: revision of the standard occupational classification. Econ. Labour Mark. Rev. 4, 48-55.

Florida, R., 2017. The New Urban Crisis: Gentrification, Housing Bubbles, Growing Inequality, and What we Can Do about it. Oneworld Publications.

Ford, A.C., Barr, S.L., Dawson, R.J., James, P., 2015. Transport accessibility analysis using GIS: assessing sustainable transport in London. ISPRS Int. J. Geo-Inf. 4, 124-149. https://doi.org/10.3390/ijgi4010124.

Geurs, K.T., van Wee, B., 2004. Accessibility evaluation of land-use and transport strategies: review and research directions. J. Transp. Geogr. 12, 127-140. https://doi. org/10.1016/j.jtrangeo.2003.10.005.

Geurs, K.T., Dentinho, T., Patuelli, R., 2016. Accessibility, Equity and Efficiency. Part 1: Introduction, in: Accessibility, Equity and Efficiency. Challenges for Transport and Public Services. Edward Elgar.

Glass, R.L., 1964. London: Aspects of Change. MacGibbon \& Kee.

Grengs, J., 2012. Equity and the social distribution of job accessibility in Detroit. Environ. Plan. B Plan. Des. 39, 785-800. https://doi.org/10.1068/b36097.

Hall, P.G., Pain, K., 2006. The Polycentric Metropolis: Learning from Mega-City Regions in Europe. Routledge.

Hamnett, C., 2003. Gentrification and the middle-class remaking of inner London, 19612001. Urban Stud. 40, 2401-2426. https://doi.org/10.1080/ 0042098032000136138.

Hamnett, C., 2015. The changing occupational class composition of London. City 19, 239-246. https://doi.org/10.1080/13604813.2015.1014711.

Hamnett, C., Reades, J., 2019. Mind the gap: implications of overseas investment for regional house price divergence in Britain. Hous. Stud. 34, 388-406. https://doi.org/ 10.1080/02673037.2018.1444151.

Handy, S.L., Niemeier, D.A., 1997. Measuring accessibility: an exploration of issues and alternatives. Environ. Plan. Econ. Space 29, 1175-1194. https://doi.org/10.1068/ a291175.

Hansen, W.G., 1959. How Accessibility Shapes Land Use. J. Am. Inst. Plann. 25, 73-76. https://doi.org/10.1080/01944365908978307. 
Hu, L., 2017. Job accessibility and employment outcomes: which income groups benefit the most? Transportation 44, 1421-1443. https://doi.org/10.1007/s11116-0169708-4.

Khan, S., 2016. In: London. Labour Party (Ed.), Sadiq Khan for London: A Manifesto for all Londoners.

Korsu, E., Wenglenski, S., 2010. Job accessibility, residential segregation and risk of longterm unemployment in the Paris region. Urban Stud. 47, 2279-2324. https://doi.org/ $10.1177 / 0042098009357962$.

Kwan, M.-P., 1998. Space-time and integral measures of individual accessibility: a comparative analysis using a point-based framework. Geogr. Anal. 30, 191-216.

Luo, W., Qi, Y., 2009. An enhanced two-step floating catchment area (E2SFCA) method for measuring spatial accessibility to primary care physicians. Health Place 15, 1100-1107. https://doi.org/10.1016/j.healthplace.2009.06.002.

Manley, D., Johnston, R., 2014. London: a dividing city, 2001-11? City 18, 633-643.

Mayor of London, 2016, 2016. The London Plan: Spatial Development Strategy for London: Consolidated with Alterations Since 2011. Greater London Authority.

Neutens, T., Schwanen, T., Witlox, F., De Maeyer, P., 2010. Equity of Urban Service delivery: a comparison of different accessibility measures. Environ. Plan. Econ. Space 42, 1613-1635. https://doi.org/10.1068/a4230.

Office for National Statistics, 2017a. Small Area Population Estimates in England and Wales: Mid-2016 [WWW Document]. https://www.ons.gov.uk/releases/ smallareapopulationestimatesinenglandandwalesmid2016.

Office for National Statistics, 2017b. Annual survey of hours and earnings by region and occupation 2016 [WWW document]. In: URL, . https://www.ons.gov.uk/ employmentandlabourmarket/peopleinwork/earningsandworkinghours/datasets/ regionbyoccupation2digitsocashetable3.

Office for National Statistics, 2018. Annual population survey 2005-2017 [WWW document]. In: URL, . https://www.nomisweb.co.uk/datasets/apsnew.

Office for National Statistics, 2016, 2016. 2011 Census aggregate data [WWW Document]. In: URL, . https://www.nomisweb.co.uk/census/2011.

Owen, A., Murphy, B., Levinson, D., 2018. Access across America: Transit 2017 Methodology.

Pereira, R.H.M., Banister, D., Schwanen, T., Wessel, N., 2018. Distributional effects of transport policies on inequalities in access to opportunities. In: Presented at the Transportation Research Board 97th Annual MeetingTransportation Research Board.

Reades, J., Smith, D.A., 2014. Mapping the 'space of flows': the geography of global business telecommunications and employment specialization in the London MegaCity-region. Reg. Stud. 48, 105-126. https://doi.org/10.1080/00343404.2013. 856515.

Rose, D., Pevalin, D., 2010. The National Statistics Socio-Economic Classification: (Rebased on the SOC2010) User Manual. 3 Palgrave Macmillan, Basingstoke, England.

Sánchez-Mateos, H.S.M., Givoni, M., 2012. The accessibility impact of a new high-speed rail line in the UK-a preliminary analysis of winners and losers. J. Transp. Geogr. 25, $105-114$.

Shen, Q., 1998. Location characteristics of Inner-City Neighborhoods and employment accessibility of low-wage workers. Environ. Plan. B Plan. Des. 25, 345-365. https:// doi.org/10.1068/b250345.

Smith, N., 1979. Toward a theory of gentrification a back to the city movement by capital, not people. J. Am. Plan. Assoc. 45, 538-548.

Smith, D., 2011. In: UCL (University College London (Ed.), Polycentricity and Sustainable Urban Form: An Intra-Urban Study of Accessibility, Employment and Travel Sustainability for the Strategic Planning of the London Region, PhD Thesis.

Smith, D.A., 2018. Employment Accessibility in the London Metropolitan Region: Developing a Multi-Modal Travel Cost Model Using OpenTripPlanner and Average Road Speed Data (No. 211), CASA Working Paper. UCL.

Social Exclusion Unit, 2003. Making the Connections: Transport and Social Exclusion. Soc. Exclusion Unit Station. Off. Lond.

Travers, T., Sims, S., Bosetti, N., 2016. Housing and inequality in London. Centre for London. https://www.centreforlondon.org/wp-content/uploads/2016/08/ CFLJ4292-London-Inequality-04_16_WEB_V4.pdf.

Wachs, M., Kumagai, T.G., 1973. Physical accessibility as a social indicator. Socio Econ. Plan. Sci. 7, 437-456. https://doi.org/10.1016/0038-0121(73)90041-4.

Watt, P., 2009. Housing stock transfers, regeneration and state-led gentrification in London. Urban Policy Res. 27, 229-242. https://doi.org/10.1080/ 08111140903154147. 